\title{
Practice guideline summary: Treatment of restless legs syndrome in adults
}

\author{
Report of the Guideline Development, Dissemination, and \\ Implementation Subcommittee of the American Academy of Neurology
}

\section{司会}

John W. Winkelman,

$\mathrm{MD}, \mathrm{PhD}$

Melissa J. Armstrong,

$\mathrm{MD}, \mathrm{MSc}$

Richard P. Allen, PhD

K. Ray Chaudhuri, MD,

FRCP, DSc

William Ondo, MD

Claudia Trenkwalder, MD

Phyllis C. Zee, MD, PhD

Gary S. Gronseth, MD

David Gloss, MD,

MPH\&TM

Theresa Zesiewicz, MD

\section{ABSTRACT}

Objective: To make evidence-based recommendations regarding restless legs syndrome (RLS) management in adults.

Methods: Articles were classified per the 2004 American Academy of Neurology evidence rating scheme. Recommendations were tied to evidence strength.

Results and recommendations: In moderate to severe primary RLS, clinicians should consider prescribing medication to reduce RLS symptoms. Strong evidence supports pramipexole, rotigotine, cabergoline, and gabapentin enacarbil use (Level A); moderate evidence supports ropinirole, pregabalin, and IV ferric carboxymaltose use (Level B). Clinicians may consider prescribing levodopa (Level C). Few head-to-head comparisons exist to suggest agents preferentially. Cabergoline is rarely used (cardiac valvulopathy risks). Augmentation risks with dopaminergic agents should be considered. When treating periodic limb movements of sleep, clinicians should consider prescribing ropinirole (Level A) or pramipexole, rotigotine, cabergoline, or pregabalin (Level B). For subjective sleep measures, clinicians should consider prescribing cabergoline or gabapentin enacarbil (Level A), or ropinirole, pramipexole, rotigotine, or pregabalin (Level B). For patients failing other treatments for RLS symptoms, clinicians may consider prescribing prolonged-release oxycodone/naloxone where available (Level C). In patients with RLS with ferritin $\leq 75 \mu \mathrm{g} / \mathrm{L}$, clinicians should consider prescribing ferrous sulfate with vitamin C (Level B). When nonpharmacologic approaches are desired, clinicians should consider prescribing pneumatic compression (Level B) and may consider prescribing near-infrared spectroscopy or transcranial magnetic stimulation (Level C). Clinicians may consider prescribing vibrating pads to improve subjective sleep (Level C). In patients on hemodialysis with secondary RLS, clinicians should consider prescribing vitamin C and $\mathrm{E}$ supplementation (Level B) and may consider prescribing ropinirole, levodopa, or exercise (Level C). Neurology ${ }^{\circledR}$ 2016;87:2585-2593

\section{GLOSSARY}

$\mathbf{A E}$ = adverse event; $\mathbf{C I}=$ confidence interval; $\mathbf{E S R D}=$ end-stage renal disease; $\mathbf{F C M}=$ ferric carboxymaltose; $\mathbf{H D}=$ hemodialysis; IRLS = International Restless Legs Syndrome Study Group rating scale; NIRS = near-infrared spectroscopy; PLMI = Periodic Limb Movement Index; PLMS = periodic limb movements of sleep; PSG = polysomnography; QoL = quality of life; RLS = restless legs syndrome; $\mathbf{r T M S}=$ repetitive transcranial magnetic stimulation; TST = total sleep time; $\mathbf{W A S O}=$ wake after sleep onset.

This document summarizes information provided in the complete guideline, available as a data supplement at Neurology.org. References e1-e20, cited in this summary, are available at Neurology.org.

Restless legs syndrome (RLS) is a movement disorder characterized by an urge to move the legs or arms, commonly in response to uncomfortable dysesthesia. Clinically important RLS affects approximately $2.5 \%$ of adults in the United States and Northern Europe, with higher prevalence in women and with increasing age. ${ }^{1}$ RLS is classified as primary or secondary in origin, with secondary RLS attributed to comorbid iron deficiency, end-stage renal disease (ESRD), or pregnancy. Most patients with RLS also have periodic limb movements of sleep (PLMS). ${ }^{2}$ Clinical consequences of RLS include impairment in sleep quality

From Harvard Medical School and Massachusetts General Hospital (J.W.W.), Boston; Department of Neurology (M.J.A.), University of Florida College of Medicine, Gainesville; Department of Neurology (R.P.A.), Johns Hopkins University, Baltimore, MD; King's College and King's College Hospital (K.R.C.), London; Methodist Neurological Institute (W.O.), Houston, TX; Department of Neurology (C.T.), University Medical Center, Göttingen, Germany; Northwestern University Feinberg School of Medicine (P.C.Z.), Chicago, IL; University of Kansas Medical Center (G.S.G.), Kansas City; CAMC Neurology Section (D.G.), Charleston, WV; and Department of Neurology (T.Z.), University of South Florida, James A Haley Veterans Administration Hospital, Tampa.

Approved by the Guideline Development, Dissemination, and Implementation Subcommittee on November 7, 2015; by the Practice Committee on December 21, 2015; and by the AAN Institute Board of Directors on August 29, 2016.

Go to Neurology.org for full disclosures. Funding information and disclosures deemed relevant by the authors, if any, are provided at the end of the article. 
and quantity, ${ }^{3}$ mood and anxiety disorders, ${ }^{4}$ worsening health-related quality of life (QoL), ${ }^{5}$ and loss of work productivity. ${ }^{6}$ Augmentation is a major side effect related to long-term RLS treatment with dopaminergic medication ${ }^{7}$ and consists of iatrogenic worsening of RLS symptoms.

This practice guideline addresses the following question: What are safe and effective therapies, including both pharmacologic and nonpharmacologic approaches, for the symptoms and clinical consequences (disturbed sleep, PLMS, depression/ anxiety, and decreased QoL) of RLS in adults?

DESCRIPTION OF THE ANALYTIC PROCESS This practice guideline follows the methodologies outlined in the 2004 edition of the American Academy of Neurology's guideline development process manual. ${ }^{8}$ A detailed description of the process is available in the full-length guideline at Neurology. org. For RLS efficacy, the International Restless Legs Syndrome Study Group rating scale (IRLS) was the preferred outcome, and a change of 3 points was considered clinically meaningful. ${ }^{9}$ For studies reporting polysomnography (PSG) results, the panel prioritized evaluating certain outcomes such as the Periodic Limb Movement Index (PLMI), total sleep time (TST), sleep efficiency, sleep latency, and wake after sleep onset (WASO). Outcomes related to subjective sleep outcomes, psychiatric symptoms, and QoL are described when available. The table presents selected adverse events (AEs), augmentation risks, and US Food and Drug Administration-approved doses for recommended medications.

Results of individual articles, including confidence intervals (CIs) and assessments of statistical significance and clinical relevance, are available in the full guideline at Neurology.org. Circumstances for which only 1 Class III study is available (for which no conclusions can be drawn, e.g., gabapentin) are also discussed only in the full guideline.

ANALYSIS OF EVIDENCE Dopamine agonists. Ropinirole. It is likely that ropinirole decreases IRLS scores at 12 weeks (meta-analysis of 2 Class I studies, ${ }^{10,11}$ of which 1 had sufficient precision independently). It is highly likely that ropinirole improves PLMS (2 Class I studies $\left.{ }^{10,11}\right)$ and likely that it improves some other objective sleep measures (1 Class I study ${ }^{11}$ ) and some subjective sleep measures (meta-analysis of 2 Class $\mathrm{I}^{10,11}$ and 4 Class II studies ${ }^{12-15}$ using Medical Outcomes Study subscales). It is likely that ropinirole improves RLS-specific QoL at 12 weeks (1 Class $\mathrm{I}^{10}$ and 3 Class II studies $\left.{ }^{12,13,15}\right)$. It is possible that ropinirole improves depression (meta-analysis of 1 Class II study ${ }^{14}$ and 1 Class I study with insufficient precision $\left.^{10}\right)$ and likely that it improves anxiety at 12 weeks (1 Class I study ${ }^{10}$ ).

Pramipexole. It is highly likely that pramipexole improves RLS symptoms as measured by the IRLS (3 Class $\mathrm{I}^{16-18}$ and 6 Class II studies ${ }^{19-24}$ over varying timeframes). It is likely that pramipexole improves PLMS (3 Class II studies ${ }^{20,22,25}$ ) and subjective sleep measures (1 Class I ${ }^{17}$ and 3 Class II studies, ${ }^{19,21,23}$ with an additional Class II study lacking the precision to exclude an important effect ${ }^{24}$ ). There is insufficient evidence to support or refute an effect of pramipexole on other polysomnographic measures (e.g., sleep latency, sleep efficiency, WASO, or TST) on the basis of results with varied statistical significance and clinical importance across 3 Class II studies ${ }^{20,22,25}$ with sometimes limited statistical reporting. It is likely that pramipexole improves RLS-specific QoL at 12 weeks (1 Class I $^{16}$ and 3 Class II studies, ${ }^{19,23,24}$ with one of the Class II studies showing limited improvement ${ }^{24}$ ). It is possible that pramipexole improves depression and anxiety at 12 weeks in patients with moderate to severe RLS-related mood disturbance (1 Class II study). ${ }^{23}$

Rotigotine. It is highly likely that the rotigotine patch improves RLS symptoms as measured by the IRLS (2 Class $\mathrm{I}^{26,27}$ and 3 Class II studies, ${ }^{28-30}$ up to 6 months in duration). It is likely that rotigotine improves PLMS (1 Class I study ${ }^{27}$ ), but there is insufficient evidence to support or refute an effect on other objective sleep measures ( 1 Class I study ${ }^{27}$ that is not statistically significant but whose CIs include clinically important effects). It is likely that rotigotine improves sleep disturbance and subjective sleep quantity (meta-analysis of 1 Class I $^{27}$ and 2 Class II studies, ${ }^{28,30}$ with 1 of the Class II studies achieving statistical significance on its $\mathrm{own}^{30}$ and the other Class I and Class II studies achieving statistical significance together). Rotigotine possibly improves sleep adequacy (meta-analysis of 1 Class $\mathrm{I}^{27}$ and 2 Class II studies ${ }^{28,30}$ that requires all 3 studies to achieve significance). Rotigotine possibly improves RLS-specific

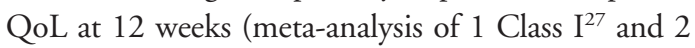
Class II studies ${ }^{28,30}$ requiring all 3 studies to achieve significance).

Cabergoline. Cabergoline is rarely used, as there are concerns regarding fibrotic complications/cardiac valvulopathy (see Discussion in the full guideline at Neurology.org).

Levodopa. Levodopa (100-200 mg) possibly improves patient-reported RLS symptom severity (4 Class III studies, ${ }^{31-34} 2$ of which show a benefit alone and 2 of which show a benefit when combined in a metaanalysis to increase statistical precision). Levodopa possibly improves subjective sleep measures (4 Class III studies, ${ }^{31-34}$ with improvements in at least some subjective sleep measures) and the PLMI (3 Class III 


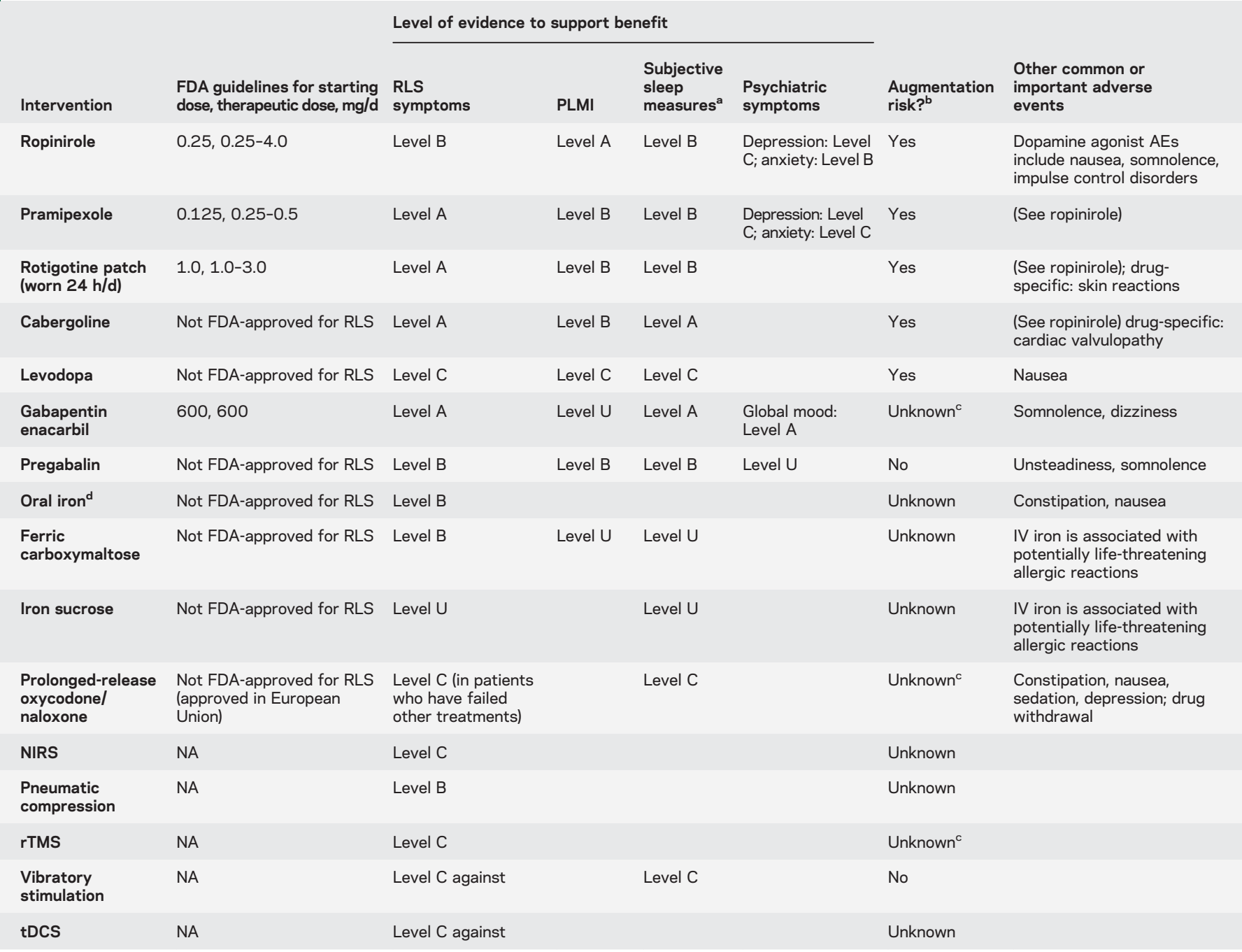

Abbreviations: AE = adverse event; FDA = US Food and Drug Administration; NA = not applicable; NIRS = near-infrared spectroscopy; PLMI = Periodic Limb Movement Index; rTMS = repetitive transcranial magnetic stimulation; tDCS = transcranial direct current stimulation.

${ }^{a}$ Level of evidence cited is the highest level of evidence identified for at least one subjective sleep rating; subjective sleep ratings are considered individually in the guideline text, with sometimes differing levels of evidence by measure. Refer to full guideline at Neurology.org for details on different subjective measures.

${ }^{\mathrm{b}}$ Augmentation marked as yes if present in $>2.4 \%$ at any timepoint in available studies (many of which are Class IV open-label long-term follow-up); the $2.4 \%$ cutoff was determined by averaging placebo augmentation responses from 3 studies (see text).

${ }^{\mathrm{c}}$ Augmentation listed as unknown because studies describing augmentation were 12 weeks or less in duration and thus cannot reliably inform augmentation risks (augmentation typically develops after at least 6 months of treatment).

${ }^{d}$ Oral studies were included only if patients had evidence of iron deficiency.

studies ${ }^{31,33,34}$ with sufficient precision and 1 Class III study $^{32}$ with insufficient precision; meta-analysis showed significant effect). There is insufficient evidence to support or refute the effect of levodopa on QoL in RLS (2 Class III studies, ${ }^{31,32}$ only 1 with sufficient precision).

$\alpha 2 \delta$ ligands. Gabapentin enacarbil. Gabapentin enacarbil is a slow-release gabapentin prodrug. It is highly likely that gabapentin enacarbil decreases IRLS scores (4 Class I studies with different study durations $^{35-38}$ ). It is highly likely that gabapentin enacarbil improves subjective sleep measures (4 Class I studies $^{35-38}$ ) and likely that it improves at least some objective sleep measures other than the PLMI (1 Class I study $\left.{ }^{35}\right)$. Because results of this Class I study were not statistically significant and CIs included both potentially clinically important and unimportant effects, there is insufficient evidence to support or refute the effect of gabapentin enacarbil on the PLMI. It is likely that gabapentin enacarbil improves RLS-specific QoL (1 Class I study ${ }^{37}$ ) and mood (1 Class I study ${ }^{36}$ ).

Pregabalin. Pregabalin likely improves IRLS scores at doses of at least $150 \mathrm{mg} / \mathrm{d}$ ( 1 Class $\mathrm{I}^{39}$ and 3 Class II studies ${ }^{24,25,40}$; there is insufficient evidence to support or refute doses of $50-100 \mathrm{mg} / \mathrm{d}$ because analyses did not reach statistical significance but CIs 
included important effects in 1 Class I study). Pregabalin likely improves the PLMI (2 Class II studies ${ }^{25,40}$ ) and likely improves at least some other objective sleep measures (1 Class $\mathrm{I}^{39}$ and 2 Class II $^{25,40}$ studies with results varying by dose and measure). Pregabalin likely improves subjective sleep outcomes (1 Class I ${ }^{39}$ and 3 Class II studies, ${ }^{24,25,40}$ 1 of which had insufficient precision at many doses). Pregabalin $300 \mathrm{mg}$ possibly improves RLS-related QoL (1 Class II study ${ }^{25}$; 1 Class I study ${ }^{39}$ reported no difference but did not provide data to assess). There is insufficient evidence to support or refute the use of pregabalin for mood in RLS.

Pregabalin vs pramipexole. There is insufficient evidence to support or refute the superiority of pregabalin over pramipexole for treating IRLS symptoms (metaanalysis of 2 Class II studies ${ }^{24,25}$ where the mean difference point estimate is not compared with pramipexole). Pregabalin likely improves subjective sleep outcomes more than pramipexole (2 Class II studies ${ }^{24,25}$ ). Pramipexole possibly improves PLMI more than pregabalin (1 Class II study ${ }^{25}$ ), whereas pregabalin possibly improves other objective sleep outcomes more than pramipexole (1 Class II study ${ }^{25}$ ). Pregabalin possibly improves QoL more than pramipexole (meta-analysis of 2 Class II studies, ${ }^{24,25}$ each with insufficient precision to drive a recommendation on its own). Pregabalin possibly has a decreased odds of augmentation at 52 weeks compared with pramipexole (1 Class II study ${ }^{24}$ ), but there is insufficient evidence to support or refute a difference at 40 weeks (1 Class II study ${ }^{24}$ with CIs including potentially important differences in both directions).

Iron treatments. Ferrous sulfate (oral). It is likely that ferrous sulfate $325 \mathrm{mg}$ with vitamin C $200 \mathrm{mg}$ taken twice daily improves RLS symptoms in patients with serum ferritin $\leq 75 \mu \mathrm{g} / \mathrm{L}$ (1 Class I study ${ }^{\mathrm{e}}$ ).

IV iron. IV ferric carboxymaltose (FCM) $500 \mathrm{mg}$ given twice 5 days apart likely improves RLS symptoms in patients with moderate to severe RLS regardless of ferritin level (1 Class I study $\left.{ }^{\mathrm{e} 2}\right)$. In this population, IV FCM likely improves RLS-specific QoL at 28 days after initial treatment (1 Class I study $\left.{ }^{\mathrm{e} 2}\right)$. There is insufficient evidence to support or refute an effect of IV FCM on subjective sleep measures or PLMI (1 Class I study ${ }^{\mathrm{e} 2}$ without statistical significance but with CIs including potentially clinically important effects). Studies investigating iron sucrose use in RLS had insufficient precision to support or refute a treatment effect (2 Class II studies ${ }^{\mathrm{e}, \mathrm{e} 4}$ did not reach statistical significance but had CIs including clinically important effects).

Opioid agonists. It is possible that prolonged-release oxycodone/naloxone (mean dose of oxycodone $21.9 \pm 15.0 \mathrm{mg}$, naloxone $11.0 \pm 7.5 \mathrm{mg}$ ) improves RLS symptoms, sleep adequacy, sleep duration, and RLS-specific QoL in patients with RLS who have not responded to other treatments (1 Class II study ${ }^{\mathrm{e}}$ ).

Other medications and nutraceuticals. Other medications and nutraceuticals are discussed in the full guideline at Neurology.org.

Physical measures. Near-infrared spectroscopy (NIRS). NIRS is possibly effective in the treatment of primary moderate to severe RLS (1 Class II study vs sham ${ }^{\mathrm{e} 6}$ and 1 Class II study showing no difference between 2 devices $^{\mathrm{e}}$ ).

Pneumatic compression. Pneumatic compression is likely effective in the treatment of patients with primary moderate to severe RLS (1 Class I study ${ }^{\mathrm{e}}$ ).

Transcranial direct current stimulation. Cathodal and anodal transcranial direct current stimulation are probably ineffective for improving RLS symptoms in women with RLS who were drug-naive (one negative Class I study ${ }^{\mathrm{e}}$ ).

Repetitive transcranial magnetic stimulation (rTMS). rTMS is possibly effective in the treatment of primary moderate to severe RLS (1 Class II study ${ }^{\mathrm{e} 10}$ ).

Vibrating pads. Vibrating pads are possibly ineffective in treating RLS symptoms (meta-analysis of 2 Class II studies ${ }^{\mathrm{e}, \mathrm{e} 10}$ excluding a clinically important benefit) but possibly effective in treating subjective sleep outcomes (meta-analysis of 2 Class II studies ${ }^{\text {e1 1,e12 }}$ where only one was sufficient to drive recommendations on its own). There is insufficient evidence to support or refute an effect of vibrating pads on QoL in RLS (meta-analysis of 2 Class II studies ${ }^{\mathrm{e} 11, \mathrm{e} 12}$ that is not statistically significant but where the $\mathrm{CI}$ includes a potentially clinically important effect).

Treatment of secondary RLS. There are many causes of secondary RLS. However, adequate evidence is available only for treatment of secondary RLS in patients with ESRD who are on hemodialysis (HD).

Ropinirole. Ropinirole $0.25 \mathrm{mg}$ daily is possibly effective in the treatment of RLS symptoms associated with ESRD/HD (1 Class II study ${ }^{\mathrm{e} 13}$ ).

Levodopa. Levodopa (100-200 mg) is possibly effective in treating PLMS associated with RLS (2 Class III studies ${ }^{32, e 14}$ ), but there is insufficient evidence to support or refute an effect of levodopa on RLS severity (2 Class III studies with insufficient precision/details $\left.{ }^{32, \mathrm{e} 14}\right)$.

Vitamins $C$ and $\boldsymbol{E}$. Vitamins C (200 mg) and E (400 $\mathrm{mg}$ ) alone and in combination are likely effective in the treatment of RLS symptoms associated with ESRD/HD (1 Class I study ${ }^{\mathrm{e} 15}$ ).

Exercise. Exercise is possibly effective in the treatment of RLS symptoms associated with ESRD/HD (1 Class II $^{\text {e16 }}$ and 3 Class III studies ${ }^{\mathrm{e} 13, \mathrm{e} 17, \mathrm{e} 18}$ with various methodologies and results). 


\section{PRACTICE RECOMMENDATIONS}

1. In moderate to severe primary RLS, clinicians should consider prescribing a pharmacologic agent to reduce RLS symptoms. There is strong evidence to support the use of pramipexole, rotigotine, cabergoline, and gabapentin enacarbil (Level A); moderate evidence to support the use of ropinirole, pregabalin, and IV FCM (Level B); and weak evidence to support the use of levodopa (Level C). There are few head-tohead comparisons of these agents to suggest that one should be used preferentially, though in practice clinicians often decide on the basis of comorbidities or potential side effects such as augmentation with dopaminergic agents. When considering efficacy alone, clinicians may consider choosing cabergoline instead of levodopa (Level C). However, cabergoline is rarely used in clinical practice for RLS because of a risk of cardiac valvulopathy at higher doses. There is insufficient evidence to support or refute the preferential use of pregabalin instead of pramipexole (Level U).

2. For patients with primary RLS for whom clinicians want to target sleep, clinicians should consider prescribing a pharmacologic agent that improves objective or subjective sleep parameters (or both). Evidence supports agents to different extents for subjective and objective outcomes.

a. When targeting PLMS, specifically the PLMI as measured by PSG, there is strong evidence to support the use of ropinirole (Level A); moderate evidence to support the use of pramipexole, rotigotine, cabergoline, and pregabalin (Level B); and weak evidence to support the use of levodopa (Level C). There is insufficient evidence to support or refute the use of gabapentin enacarbil, FCM, or iron sucrose for PLMS (Level U). There is weak evidence (Level C) for using pramipexole in preference to pregabalin with regard to PLMI alone.

b. With regard to other objective sleep measures (e.g., TST, sleep efficiency, sleep latency, and WASO), there is moderate evidence to support the use of ropinirole, gabapentin enacarbil, and pregabalin for at least some objective sleep measures (Level B). There is insufficient evidence to support or refute the use of pramipexole, rotigotine, cabergoline, or levodopa for these measures (Level U). There is weak evidence (Level C) for using pregabalin in preference to pramipexole with regard to objective sleep measures other than PLMI. c. With regard to subjective sleep measures, there is strong evidence to support the use of cabergoline and gabapentin enacarbil (Level A); moderate evidence to support the use of ropinirole, pramipexole, and pregabalin (Level B); weak to moderate evidence to support the use of rotigotine (Levels B and C); and weak evidence to support the use of levodopa (Level C), with the strength of evidence varying by measure and, sometimes, dose. There is insufficient evidence to support or refute the use of FCM for subjective sleep measures (Level $\mathrm{U})$. There is moderate evidence to support the use of pregabalin instead of pramipexole with regard to subjective sleep outcomes (Level B).

3. For patients with RLS for whom clinicians want to target concomitant psychiatric symptoms, clinicians should consider ropinirole in the context of anxiety (Level B) and may consider ropinirole in the context of depression (Level C). In the context of moderate to severe RLS-related mood disturbance, clinicians may consider prescribing pramipexole for depression and anxiety (Level C). For overall mood, clinicians should consider prescribing gabapentin enacarbil (Level B).

4. For patients with RLS for whom clinicians want to select an agent that improves QoL, clinicians should consider prescribing ropinirole, pramipexole, cabergoline, gabapentin enacarbil, or IV FCM (Level B) and may consider prescribing rotigotine or pregabalin (Level C). There is insufficient evidence to support or refute the use of levodopa for improving QoL in RLS (Level U).

5. When avoidance of augmentation is a deciding factor, clinicians may consider prescribing pregabalin rather than pramipexole when considering 52-week treatment in light of lower augmentation rates with pregabalin (Level C). Clinicians may also consider prescribing cabergoline rather than levodopa when considering 30-week treatment in light of lower augmentation rates with cabergoline (Level C); however, this needs to be weighed against the risk of cardiac valvulopathy with high doses of cabergoline. There is insufficient evidence to support or refute which dopaminergic agents cause the least augmentation because augmentation rates are most commonly reported in long-term open-label Class IV studies (Level U). Results of these studies are summarized in the full guideline at Neurology.org but cannot support formal recommendations.

6. For patients with RLS who have not responded to other treatments, clinicians may consider 
prescribing prolonged-release oxycodone/naloxone (where available) for RLS symptoms, subjective sleep symptoms, and QoL (Level C), but potential benefits need to be weighed against known opioid risks.

7. There is insufficient evidence to support or refute the use of gabapentin, iron sucrose, oxycodone, clonazepam, bupropion, clonidine, selenium, rifaximin, botulinum neurotoxin, valproic acid, carbamazepine, or valerian in the treatment of RLS (Level U).

8. For patients or clinicians wanting to use nonpharmacologic approaches to treat RLS, clinicians should consider prescribing pneumatic compression before usual symptom onset (Level B) and may consider prescribing NIRS or rTMS (where available) (Level C). Clinicians may consider prescribing vibrating pads for subjective sleep concerns (Level C) but not for RLS symptoms (Level $\mathrm{C}$ against). Clinicians may also choose not to consider transcranial direct current stimulation for RLS symptoms (Level C against). There is insufficient evidence to support or refute use of acupuncture in RLS (Level U).

9. In patients with RLS and serum ferritin $\leq 75 \mu \mathrm{g} / \mathrm{L}$, clinicians should consider prescribing ferrous sulfate with vitamin $\mathrm{C}$ for improvement of RLS symptoms (Level B).

10. In patients with secondary RLS associated with ESRD on HD, clinicians should consider prescribing vitamin $\mathrm{C}$ and $\mathrm{E}$ supplementation (alone or in combination) (Level B) and may consider prescribing ropinirole, levodopa, or exercise (Level C). There is insufficient evidence to support or refute the use of gabapentin or IV iron dextran in RLS associated with ESRD/HD (Level U). There is also insufficient evidence to support or refute the use of gabapentin or levodopa preferentially over the other in this population (Level U).

CLINICAL CONTEXT When addressing RLS, clinicians and patients must first determine whether symptoms require treatment, the setting in which this practice guideline is relevant. Treatment should be considered if RLS symptoms interfere with sleep or daytime function to an important degree. Before determining the best treatment, it is important to first ensure there are no contributing factors to RLS symptoms (e.g., iron deficiency or serotonergic antidepressants). Because iron deficiency is a known contributor to RLS, can result in other complications, and may respond to iron supplementation, it is reasonable for clinicians to check iron studies in patients with RLS with new or worsening symptoms and treat the iron deficiency first if indicated.
There are important limitations in the evidence regarding RLS treatments. The clinical significance of some outcomes used in RLS trials, such as PLMI, is uncertain; thus conclusions drawn regarding these outcomes are of unknown clinical relevance. In addition, apart from the IRLS, clinically important differences for the measures used in RLS trials are unknown. Most of the studies are short-term trials, often 12 or fewer weeks, whereas clinical treatment of RLS is ongoing over years. Conclusions regarding long-term efficacy and risks are difficult to develop because of the open-label nature of many longer duration studies. Short-term trials are less able to inform risks associated with prolonged medication exposure, such as augmentation occurring with dopaminergic medications. Augmentation is a major concern and an important consideration when choosing a treatment approach. Long-term risks with other treatment approaches, such as opioid use, are also important to consider.

Though some patients have RLS symptoms intermittently, the value of PRN medications is unknown. ${ }^{1}$ Additionally, there are no data to guide the approach to cases where monotherapy is not adequately effective or clinicians want to use multiple agents to minimize doses of dopaminergic agents. Clinical trials of RLS medications generally exclude patients with common comorbid conditions such as mood and anxiety disorders and peripheral neuropathy. Generalizability of studies to populations with these disorders is uncertain. ${ }^{\mathrm{e} 19}$ Certain populations with secondary RLS, such as pregnant women, are also under-studied.

In patients with RLS symptoms requiring treatment, choosing the most appropriate intervention requires an individualized approach including regard for patient factors, such as the most prominent symptoms (e.g., presence of sleep disturbance, because of varying strength of evidence by outcome), comorbidities relating to RLS (e.g., mood), other comorbidities (such that an agent may be used preferentially to treat more than one indication or avoided because of a presumed higher risk of side effects), age, side effect profile, augmentation risks, and patient preferences (e.g., pharmacologic or nonpharmacologic approaches). In addition to AEs commonly reported in trials, some agents for RLS have less common but important risks, including cardiac valvulopathy with cabergoline and impulse control disorders with dopamine agonists.

Given the chronicity of RLS, long-term risks of augmentation with dopaminergic agents are relevant for many patients. Scant data exist to guide the decision-making process relating to augmentation. ${ }^{\text {e20 }}$ For patients on dopaminergic agents, careful reassessment of changes in the time of symptom onset, anatomical distribution, total medication dose, and 
medication timing are indicated at least yearly. In the absence of evidence, it is reasonable to consider discontinuing a patient's dopaminergic medication in the setting of clinically important augmentation and switching to a nondopaminergic agent or a longeracting dopaminergic medication.

DISCLAIMER Clinical practice guidelines, practice advisories, systematic reviews, and other guidance published by the American Academy of Neurology (AAN) and its affiliates are assessments of current scientific and clinical information provided as an educational service. The information (1) should not be considered inclusive of all proper treatments, methods of care, or as a statement of the standard of care; (2) is not continually updated and may not reflect the most recent evidence (new evidence may emerge between the time information is developed and when it is published or read); (3) addresses only the question(s) specifically identified; (4) does not mandate any particular course of medical care; and (5) is not intended to substitute for the independent professional judgment of the treating provider, as the information does not account for individual variation among patients. In all cases, the selected course of action should be considered by the treating provider in the context of treating the individual patient. Use of the information is voluntary. The AAN provides this information on an "as is" basis and makes no warranty, expressed or implied, regarding the information. The AAN specifically disclaims any warranties of merchantability or fitness for a particular use or purpose. The AAN assumes no responsibility for any injury or damage to persons or property arising out of or related to any use of this information or for any errors or omissions.

CONFLICT OF INTEREST The American Academy of Neurology (AAN) is committed to producing independent, critical, and truthful clinical practice guidelines (CPGs). Significant efforts are made to minimize the potential for conflicts of interest to influence the recommendations of this CPG. To the extent possible, the AAN keeps separate those who have a financial stake in the success or failure of the products appraised in the CPGs and the developers of the guidelines. Conflict of interest forms were obtained from all authors and reviewed by an oversight committee prior to project initiation. The AAN limits the participation of authors with substantial conflicts of interest. The AAN forbids commercial participation in, or funding of, guideline projects. Drafts of the guideline have been reviewed by at least 3 AAN committees, a network of neurologists, Neurology ${ }^{\circledR}$ peer reviewers, and representatives from related fields. The AAN
Guideline Author Conflict of Interest Policy can be viewed at aan.com. For complete information on this process, access the 2004 AAN process manual. ${ }^{8}$

\section{AUTHOR CONTRIBUTIONS}

Dr. Winkelman: study concept and design, acquisition of data, analysis or interpretation of data, drafting/revising the manuscript, critical revision of the manuscript for important intellectual content, study supervision. Dr. Armstrong: study concept and design, acquisition of data, analysis or interpretation of data, drafting/revising the manuscript, critical revision of the manuscript for important intellectual content, study supervision. Dr. Allen: study concept and design, acquisition of data, analysis or interpretation of data, drafting/revising the manuscript, critical revision of the manuscript for important intellectual content. Dr. Chaudhuri: study concept and design, acquisition of data, analysis or interpretation of data, drafting/revising the manuscript, critical revision of the manuscript for important intellectual content. Dr. Ondo: study concept and design, acquisition of data, analysis or interpretation of data, drafting/revising the manuscript, critical revision of the manuscript for important intellectual content. Dr. Trenkwalder: study concept and design, acquisition of data, analysis or interpretation of data, drafting/revising the manuscript, critical revision of the manuscript for important intellectual content. Dr. Zee: study concept and design, acquisition of data, analysis or interpretation of data, drafting/revising the manuscript, critical revision of the manuscript for important intellectual content. Dr. Gronseth: study concept and design, acquisition of data, analysis or interpretation of data, drafting/revising the manuscript, critical revision of the manuscript for important intellectual content, study supervision. Dr. Gloss: acquisition of data, analysis or interpretation of data, drafting/revising the manuscript, critical revision of the manuscript for important intellectual content. Dr. Zesiewicz: study concept and design, acquisition of data, analysis or interpretation of data, drafting/revising the manuscript, critical revision of the manuscript for important intellectual content, study supervision.

\section{STUDY FUNDING}

This guideline was developed with financial support from the American Academy of Neurology. Authors who serve or served as AAN subcommittee members or methodologists (M.J.A., G.S.G., D.G., T.Z.) were reimbursed by the AAN for expenses related to travel to subcommittee meetings where drafts of manuscripts were reviewed.

\section{DISCLOSURE}

J. Winkelman currently serves on scientific advisory boards for Merck and Flex Pharma and has served on scientific advisory boards for UCB, Impax, Pfizer, Lacrima, Luitpold Pharmaceuticals, GlaxoSmithKline, Boehringer-Ingelheim, Xenoport, Zeo Inc., Sunovion, Insys, Takeda, Jazz, and Neurogen; currently performs neurophysiology studies as part of his practice; currently serves as a journal editor for the following publications: Sleep, Sleep Medicine, and CNS Drugs; has received honoraria from or served on speakers bureaus for the following organizations: Boehringer-Ingelheim, GlaxoSmithKline, Pfizer, Sepracor (now Sunovion), Takeda, Luitpold Pharmaceuticals, Novartis, Neurogen, and UCB (Schwarz Pharma); has received research support from Boehringer-Ingelheim, GlaxoSmithKline, UCB (Schwarz Pharma), Sepracor (now Sunovion), and Pfizer; holds stock in Flex Pharma; receives publishing royalties for the following publications: Foundations of Psychiatric Sleep Medicine (Cambridge University Press, 2010) and an UpToDate chapter on nocturnal leg cramps; receives government research support from the National Institute of Mental Health (1RO1MH095792-01A1, PI); and has given expert testimony for legal cases representing generic manufacturers of pharmaceuticals approved for the treatment of insomnia and narcolepsy. M. Armstrong receives compensation from the American Academy of Neurology (AAN) as an evidence-based medicine methodologist and serves on the Level of Evidence editorial board for Neurology but is not compensated financially. R. Allen has served on a volunteer basis for the International Restless Legs Syndrome Study Group and the World Association of Sleep Medicine; has served on scientific advisory boards for Pfizer, GlaxoSmithKline, 
Boehringer Ingelheim, Jazz Pharmaceuticals, UCB, Luitpold, and Xenoport; has received funding for travel from UCB; currently serves as a field editor for the journal Sleep Medicine; has served as a journal editor for the following journals: Sleep Medicine, Sleep, and Movement Disorders; receives publishing royalties from Sleep and Movement Disorders; has received honoraria from UCB for CME; currently serves as a consultant for Luitpold Pharmaceuticals; holds a patent (PCT/US15/15556) for a device and method for detection of periodic leg movements; and has received research support from GlaxoSmithKline, Pharmacosmos, and the NIH. K. Chaudhuri has served as a journal editor-in-chief for Nature Parkinson Journal and as editor for Basal Ganglia; receives publishing royalties from the following publications: Non-Motor Symptoms of Parkinson's Disease, Oxford University Press, 2nd edition, 2014, and 1st edition, 2011; has received honoraria from Parkinson's UK, the National Institute of Health Research (NIHR), the International Parkinson and Movement Disorder Society, Parkinson's UK and EU, and UCB, and for sponsored symposiums from UCB, AbbVie, Britannia, US Worldmeds, Otsuka, Medtronic, and Zambon; has served as a consultant for AbbVie, UCB, Britannia, Medtronic, and Mundipharma; currently serves on a scientific advisory board for Mundipharma and has served on a scientific advisory board for Eli Lilly in April of 2013; has received research support from Britannia and UCB (in the form of educational grants), from the NIHR (UK and EU both, for development of a nonmotor symptoms questionnaire for RLS), and from Parkinson's UK (in the form of the following awards: 2016-2018: Horizon 2020 award: i-PROGNOSIS Intelligent Parkinson Early Detection Guiding Novel Supportive Interventions, 2015-2016: CRN South London contingency funding, and 2014 2016: International Parkinson's and Movement Disorders Society: Field Validation of the MDS-NMS Scale); and currently receives license fee payments for the following scales: the King's Parkinson's Disease Pain Scale and the revised Parkinson's Disease Sleep Scale. W. Ondo serves on speakers bureaus for Teva, Lundbeck, Merz, UCB, Xenoport, and Avanir; has received research support in the form of grants from USWorld Meds, Cynapsus, Dystonia Coalition, Tremor Research Group, Huntington Study Group, Auspex, and InSightec; serves on the Neurology Level of Evidence editorial advisory board; and receives royalties for co-editing the UpToDate publication Restless Legs Syndrome. C. Trenkwalder has served on scientific advisory boards for Britannia, UCB, Mundipharma, Novartis, Vifor, and Desitin; has received honoraria from UCB, Mundipharma, Desitin, Britannia, and GlaxoSmithKline; has received grants from Teva, Mundipharma, Horizon 2020 European Frame Work Program, and the Michael J. Fox Foundation; has served as an investigator for Mundipharma, Novartis, and Vifor; has received research support from Mundipharma and Teva; and has received publishing royalties from Schattauer for Parkinson and from Thieme (Georg Thieme Verlag) for Parkinson Disease and for guidelines on RLS from the German Neurologic Society. P. Zee currently serves on scientific advisory boards for Merck, Phillips, and Eisai; has served on scientific advisory boards for Sanofi, Merck, Aptalis, Jazz, Vanda, Ferring, Takeda, UCB, Purdue, Pernix, and Phillips; serves as the deputy editor for Sleep and for the Journal of Sleep Medicine; has served as an associate editor for Sleep and as single-issue editor for the journal Sleep Medicine Clinics; holds a patent on a light therapy visor; receives publishing royalties from Wolters Kluwer for various books; has received honoraria from Merck, Aptalis, Jazz, Vanda, and Ferring; has received research support from Boehringer Ingelheim Pharmaceuticals, Inc. and GlaxoSmithKline for studies related to RLS, and from Takeda Pharmaceuticals, Jazz, Philips Consumer Lifestyle International B.V., the NIH, the American Academy of Sleep Medicine, and Northwestern Memorial Foundation (for studies not related to RLS); serves on the American Board of Internal Medicine test-writing committee for the Sleep Medicine Board Exam; has received honoraria for numerous speaking engagements; and has held stock in Teva. G. Gronseth serves as an associate editor for Neurology and as an editorial advisory board member of Neurology Now, and receives compensation from the AAN for work as the chief evidencebased medicine methodologist. D. Gloss serves as an evidence-based medicine consultant for the AAN. T. Zesiewicz serves on the editorial boards of Tremor and Other Hyperkinetic Disorders and Neurodegenerative Disease Management and has received research support for work on the Friedreich's Ataxia Research Alliance. Go to Neurology.org for full disclosures.

Received March 22, 2016. Accepted in final form August 2, 2016.

\section{REFERENCES}

1. Allen RP, Walters AS, Montplaisir J, et al. Restless legs syndrome prevalence and impact: REST general population study. Arch Inter Med 2005;165:1286-1292.

2. Zucconi M, Ferri R, Allen R, et al; for the International Restless Legs Syndrome Study Group. The official World Association of Sleep Medicine (WASM) standards for recording and scoring periodic leg movements in sleep (PLMS) and wakefulness (PLMW) developed in collaboration with a task force from the International Restless Legs Syndrome Study Group (IRLSSG). Sleep Med 2006;7:175-183.

3. Winkelman JW, Redline S, Baldwin CM, Resnick HE, Newman AB, Gottlieb DJ. Polysomnographic and health-related quality of life correlates of restless legs syndrome in the Sleep Heart Health Study. Sleep 2009;32: $772-778$

4. Hornyak M. Depressive disorders in restless legs syndrome: epidemiology, pathophysiology and management. CNS Drugs 2010;24:89-98.

5. Reinhold T, Müller-Riemenschneider F, Willich SN, Brüggenjürgen B. Economic and human costs of restless legs syndrome. Pharmacoeconomics 2009;27:267-279.

6. Allen RP, Bharmal M, Calloway M. Prevalence and disease burden of primary restless legs syndrome: results of a general population survey in the United States. Mov Disord 2011;26:114-120.

7. Garcia-Borreguero D, Williams AM. Dopaminergic augmentation of restless legs syndrome. Sleep Med Rev 2010; 14:339-346.

8. American Academy of Neurology. Clinical Practice Guideline Process Manual. 2004 ed. St. Paul: American Academy of Neurology; 2004:1-57.

9. Allen RP. Minimal clinically significant change for the International Restless Legs Syndrome Study Group rating scale in clinical trials is a score of 3. Sleep Med 2013;14:1229.

10. Bogan RK, Fry JM, Schmidt MH, Carson SW, Ritchie SY; for the TREAT RLS US Study Group. Ropinirole in the treatment of patients with restless legs syndrome: a US-based randomized, double-blind, placebo-controlled clinical trial. Mayo Clin Proc 2006;81:17-27.

11. Allen R, Becker PM, Bogan R, et al. Ropinirole decreases periodic leg movements and improves sleep parameters in patients with restless legs syndrome. Sleep 2004;27:907-914.

12. Trenkwalder C, Garcia-Borreguero D, Montagna P, et al; for the Therapy with Ropinirole; Efficacy and Tolerability in RLS 1 Study Group. Ropinirole in the treatment of restless legs syndrome: results from the TREAT RLS 1 study, a 12 week, randomised, placebo controlled study in 10 European countries. J Neurol Neurosurg Psychiatry 2004;75:92-97.

13. Walters AS, Ondo WG, Dreykluft T, Grunstein R, Lee D, Sethi K; for the TREAT RLS 2 (Therapy with Ropinirole: Efficacy And Tolerability in RLS 2) Study Group. Ropinirole is effective in the treatment of restless legs syndrome. TREAT RLS 2: a 12-week, double-blind, randomized, parallel-group, placebo-controlled study. Mov Disord 2004;19:1414-1423.

14. Benes H, Mattern W, Peglau I, et al. Ropinirole improves depressive symptoms and restless legs syndrome severity in RLS patients: a multicentre, randomized, placebocontrolled study. J Neurol 2011;258:1046-1054.

15. Giorgi L, Asgharian A, Hunter B. Ropinirole in patients with restless legs syndrome and baseline IRLS total scores 
$\geq 24$ : efficacy and tolerability in a 26 -week, double-blind, parallel-group, placebo-controlled study followed by a 40 week open-label extension. Clin Ther 2013;35:1321-1336.

16. Winkelman JW, Sethi KD, Kushida CA, et al. Efficacy and safety of pramipexole in restless legs syndrome. Neurology 2006;67:1034-1039.

17. Ma JF, Wan Q, Hu XY, et al. Efficacy and safety of pramipexole in Chinese patients with restless legs syndrome: results from a multi-center, randomized, doubleblind, placebo-controlled trial. Sleep Med 2011;13:58-63.

18. Zhang J, Liu B, Zheng Y, Chu T, Yang Z. Pramipexole for Chinese people with primary restless legs syndrome: a 12week multicenter, randomized, double-blind study. Sleep Med 2015;16:181-185.

19. Ferini-Strambi L, Aarskog D, Partinen M, et al. Effect of pramipexole on RLS symptoms and sleep: a randomized, double-blind, placebo-controlled trial. Sleep Med 2008;9: 874-881.

20. Partinen M, Hirvonen K, Jama L, et al. Efficacy and safety of pramipexole in idiopathic restless legs syndrome: a polysomnographic dose-finding study: the PRELUDE study. Sleep Med 2006;7:407-417.

21. Oertel WH, Stiasny-Kolster K, Bergtholdt B, et al; for the Pramipexole RLS Study Group. Efficacy of pramipexole in restless legs syndrome: a six-week, multicenter, randomized, double-blind study (effect-RLS study). Mov Disord 2007;22:213-219.

22. Jama L, Hirvonen K, Partinen M, et al. A dose-ranging study of pramipexole for the symptomatic treatment of restless legs syndrome: polysomnographic evaluation of periodic leg movements and sleep disturbance. Sleep Med 2009;10:630-636.

23. Montagna P, Hornyak M, Ulfberg J, et al. Randomized trial of pramipexole for patients with restless legs syndrome (RLS) and RLS-related impairment of mood. Sleep Med 2011;12:34-40.

24. Allen RP, Chen C, Garcia-Borreguero D, et al. Pregabalin versus pramipexole for restless legs syndrome. N Engl J Med 2014;370:635-643.

25. Garcia-Borreguero D, Patrick J, DuBrava S, et al. Pregabalin versus pramipexole: effects on sleep disturbance in restless legs syndrome. Sleep 2014;37:635-643.

26. Stiasny-Kolster K, Kohnen R, Schollmayer E, Mőller JC, Oertel WH; for the Rotigotine Sp 666 Study Group. Patch application of the dopamine agonist rotigotine to patients with moderate to advanced stages of restless legs syndrome: a double-blind, placebo-controlled pilot study. Mov Disord 2004;19:1432-1438.

27. Oertel WH, Benes H, Garcia-Borreguero D, et al. Rotigotine transdermal patch in moderate to severe idiopathic restless legs syndrome: a randomized, placebo-controlled polysomnographic study. Sleep Med 2010;11:848-856.

28. Hening WA, Allen RP, Ondo WG, et al; for the SP792 Study Group. Rotigotine improves restless legs syndrome: a 6-month randomized, double-blind, placebo- controlled trial in the United States. Mov Disord 2010;25:1675-1683.

29. Inoue Y, Shimizu T, Hirata K, et al; for the Rotigotine Trial Group. Efficacy and safety of rotigotine in Japanese patients with restless legs syndrome: a phase 3 , multicenter, randomized, placebo-controlled, double-blind, parallel-group study. Sleep Med 2013;14:1085-1091.

30. Trenkwalder C, Benes H, Poewe W, et al; for the SP790 Study Group. Efficacy of rotigotine for treatment of moderate-to-severe restless legs syndrome: a randomised, double-blind, placebo-controlled trial. Lancet Neurol 2008;7:595-604.

31. Benes H, Kurella B, Kummer J, Kazenwadel J, Selzer R, Kohnen R. Rapid onset of action of levodopa in restless legs syndrome: a double-blind, randomized, multicenter, crossover trial. Sleep 1999;22:1073-1081.

32. Trenkwalder C, Stiasny K, Pollmächer T, et al. L-dopa therapy of uremic and idiopathic restless legs syndrome: a double-blind, crossover trial. Sleep 1995;18:681-688.

33. Brodeur C, Montplaisir J, Godbout R, Marinier R. Treatment of restless legs syndrome and periodic movements during sleep with L-dopa: a double-blind, controlled study. Neurology 1988;38:1845-1848.

34. Eisensehr I, Ehrenberg BL, Rogge Solti S, Noachtar S. Treatment of idiopathic restless legs syndrome (RLS) with slow-release valproic acid compared with slow-release levodopa/benserazid. J Neurol 2004;251:579-583.

35. Kushida CA, Walters AS, Becker P, et al; for the XP021 Study Group. A randomized, double-blind, placebocontrolled, crossover study of XP13512/GSK1838262 in the treatment of patients with primary restless legs syndrome. Sleep 2009;32:159-168.

36. Walters AS, Ondo WG, Kushida CA, et al; for the XP045 Study Group. Gabapentin enacarbil in restless legs syndrome: a phase 2 b, 2-week, randomized, double-blind, placebocontrolled trial. Clin Neuropharmacol 2009;32:311-320.

37. Kushida CA, Becker PM, Ellenbogen AL, Canafax DM, Barrett RW. for the XP052 Study Group. Randomized, double-blind, placebo-controlled study of XP13512/GSK1838262 in patients with RLS. Neurology 2009;72:439-446.

38. Lee DO, Ziman RB, Perkins AT, Poceta JS, Walters AS, Barrett RW, for the XP053 Study Group. A randomized, double-blind, placebo-controlled study to assess the efficacy and tolerability of gabapentin enacarbil in subjects with restless legs syndrome. J Clin Sleep Med 2011;7: 282-292.

39. Allen R, Chen C, Soaita A, et al. A randomized, doubleblind, 6-week, dose-ranging study of pregabalin in patients with restless legs syndrome. Sleep Med 2010;11:512-519.

40. Garcia-Borreguero D, Larrosa O, Williams AM, et al. Treatment of restless legs syndrome with pregabalin: a double-blind, placebo-controlled study. Neurology 2010;74: 1897-1904. 


\section{Neurology}

Practice guideline summary: Treatment of restless legs syndrome in adults: Report of the Guideline Development, Dissemination, and Implementation Subcommittee of the American Academy of Neurology

John W. Winkelman, Melissa J. Armstrong, Richard P. Allen, et al.

Neurology 2016;87;2585-2593 Published Online before print November 16, 2016

DOI 10.1212/WNL.0000000000003388

This information is current as of November 16, 2016

\section{Updated Information \&} Services

Supplementary Material

\section{References}

Citations

Subspecialty Collections

Permissions \& Licensing

Reprints including high resolution figures, can be found at: http://n.neurology.org/content/87/24/2585.full

Supplementary material can be found at: http://n.neurology.org/content/suppl/2016/11/16/WNL.0000000000003 388.DC1

http://n.neurology.org/content/supp1/2016/12/12/WNL.0000000000003 388.DC2

This article cites 39 articles, 5 of which you can access for free at: http://n.neurology.org/content/87/24/2585.full\#ref-list-1

This article has been cited by 3 HighWire-hosted articles: http://n.neurology.org/content/87/24/2585.full\#\#otherarticles

This article, along with others on similar topics, appears in the following collection(s):

All Movement Disorders

http://n.neurology.org/cgi/collection/all_movement_disorders Restless legs syndrome

http://n.neurology.org/cgi/collection/restless_legs_syndrome

Information about reproducing this article in parts (figures,tables) or in its entirety can be found online at:

http://www.neurology.org/about/about_the_journal\#permissions

Information about ordering reprints can be found online:

http://n.neurology.org/subscribers/advertise

Neurology ${ }^{\circledR}$ is the official journal of the American Academy of Neurology. Published continuously since 1951, it is now a weekly with 48 issues per year. Copyright @ 2016 American Academy of Neurology. All rights reserved. Print ISSN: 0028-3878. Online ISSN: 1526-632X.

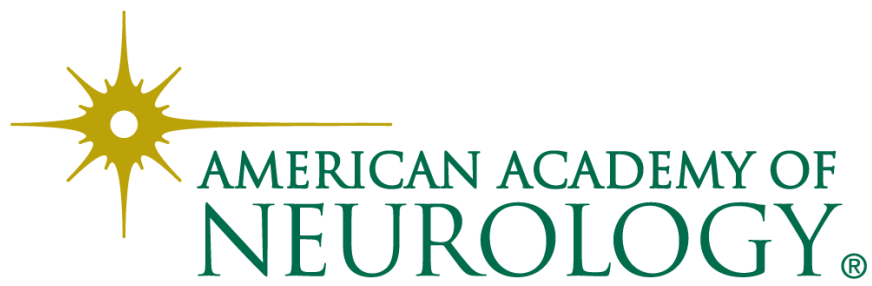

